\title{
Macunaíma, de Mário de Andrade, e Os flagelados do vento leste, de Manuel Lopes: leituras encantadas da tradição oral
}

Avani Souza Silva

\begin{abstract}
Resumo
O objetivo deste artigo é analisar, por meio do Comparatismo de Solidariedade (ABDALA JUNIOR, 2003), duas obras pertencentes ao macrossistema literário de língua portuguesa: Macunaíma (1928), do brasileiro Mário de Andrade, e Os flagelados do vento leste (1968), do cabo-verdiano Manuel Lopes. Examinaremos as marcas da oralidade presentes nas obras, assinalando pontos de contato e ruptura com os respectivos contextos socioculturais nos quais elas foram concebidas. Como justificativa para a comparação, ressaltamos que, assim como no Modernismo Brasileiro, um dos postulados do movimento cultural da "caboverdianidade" - de que Manuel Lopes foi um dos adeptos - era a valorização estética do nacional, especialmente em relação à tradição oral.

Palavras-chave: macrossistema literário, tradição oral, literatura cabo-verdiana, literatura comparada, comparatismo de solidariedade
\end{abstract}

Recebido em 06 de maio de 2015 Aceito em 15 de dezembro de 2015

\footnotetext{
${ }^{a}$ Doutora em Letras pelo Programa de Pós-Graduação em Estudos Comparados de Literaturas de Língua Portuguesa da Faculdade de Letras da USP, avanissilva@yahoo.com.br.
} 
Neste trabalho, comparamos duas obras pertencentes ao macrossistema literário de língua portuguesa: Macunaíma, do brasileiro Mário de Andrade, e Os flagelados do vento leste, do cabo-verdiano Manuel Lopes. Enfatizando a oralidade que permeia as duas obras, nossas análises inserem-se no âmbito da Literatura Comparada (CARVALHAL, 2003; PERRONE MOISÉS, 1990) e do Comparatismo de Solidariedade (ABDALA JUNIOR, 2003).

Benjamin Abdala Junior formulou o conceito de macrossistema das literaturas de língua portuguesa a partir da conceituação de sistema literário, concebido por Antonio Candido na sua obra Formação da Literatura Brasileira (1975). Para o crítico brasileiro Antonio Candido, o sistema literário é um complexo simbólico constituído com base no trinômio escritorobra-leitor, em um continuum produtivo literário. Quando a atividade dos escritores, em dado período sócio-histórico, se integra nesse sistema possibilitando uma continuidade literária, instaura-se a tradição literária. Para explicar essa continuidade, Antonio Candido recorre à imagem de uma tocha que passa de mão em mão entre corredores. Assim, veiculadas por uma tradição literária, o conjunto de obras ligadas em diversos momentos históricos, num continuum, constitui o sistema literário (CANDIDO, 1975, p. 23-24).

No caso de Cabo Verde, podemos situar a dinamização de seu sistema literário a partir da criação da Claridade Revista de Artes e Letras, em 1936, que possibilitou o advento de várias publicações, sendo que em seu primeiro número trouxe um capítulo do primeiro romance moderno cabo-verdiano: Chiquinho, de Baltasar Lopes, além de textos tematizando a tradição oral do arquipélago e outros em língua cabo-verdiana, revelando os postulados da caboverdianidade assumidos pela Revista. É de ressaltar, por sua importância histórica, que a primeira edição de Chiquinho, romance de formação, data de 1947, em Lisboa. A obra apresenta inquestionável ressonância no público infanto-juvenil, pela sua temática, seu contexto cultural da Ilha de São Nicolau, personagens e estórias contadas pelo narrador e pelas personagens, inserindo-se, na nossa opinião, como a primeira obra literária crioula do gênero Literatura Infantil e Juvenil.

Destacamos, contudo, que O escravo, publicado em Lisboa em 1856, de José Evaristo de Almeida - português radicado 
em Cabo Verde - é considerado o primeiro romance caboverdiano, uma vez que se situa no espaço geográfico e social do arquipélago, trazendo suas marcas históricas e culturais. Para Simone Caputo Gomes, o romance O escravo "se enquadra no âmbito da literatura cabo-verdiana", sendo "considerado o primeiro do percurso literário crioulo" (GOMES, 2008, p. 3).

O macrossistema das literaturas de língua portuguesa engloba todos os sistemas literários consolidados como tal ou em formação nos países de língua portuguesa, e se organiza em diálogos e trocas, tendo aportes culturais próprios a cada um dos sistemas e comuns entre eles e o macrossistema a que pertencem, de modo que o alheio esteja sempre em contato com o próprio de cada literatura. Vinculam-se ao macrossistema todos os sistemas literários de língua portuguesa, independentemente do estágio de sua emergência e consolidação.

Qualquer análise que coloca em relação duas ou mais literaturas - como o confronto de obras, de autores, de movimentos literários, de elementos estruturais da narrativa, de temas, da recepção, ou mesmo da fortuna crítica dos autores - está no âmbito da Literatura Comparada, como bem definido por Leyla Perrone Moisés, em sua obra Flores sobre a escrivaninha (1990, p. 91). Portanto, o confronto temático de obras pertencentes ao macrossistema de literaturas de língua portuguesa, como Os flagelados do vento leste e Macunaíma, está contemplado no âmbito da Literatura Comparada.

Nesse sentido, dois elementos que nos chamaram a atenção no cotejo preliminar das obras foram o tema da fome e o recurso à tradição oral como elementos estruturais de suas construções narrativas. Assim, para comparar referidas obras, baseamo-nos no Comparatismo de Solidariedade, teorizado por Benjamin Abdala Junior, que ele contrapõe ao Comparatismo de Necessidade. O primeiro privilegia as articulações comunitárias entre os países periféricos com a maior circulação de repertórios culturais comuns. O segundo, baseado no conceito de fontes e influências, geralmente privilegia os modelos literários com suas implicações ideológicas, dentre as quais a superioridade de uma literatura em relação a outras. Assim, consideraremos as duas obras como estando no mesmo nível de igualdade e de importância, rejeitando qualquer noção de supremacia de uma em relação à outra, sob qualquer prisma. 
A literatura cabo-verdiana é jovem e, como dissemos, a revista Claridade, publicada em 1936, é tida como marco importante do incremento da produção literária no arquipélago. Anteriormente à Claridade, havia no Arquipélago e na diáspora manifestações literárias que, como afirma Antonio Candido, não pressupõem a existência do sistema literário respectivo. Se os países africanos colonizados por Portugal tinham como espelho ou como fonte inspiradora a literatura produzida na metrópole, como nos casos de Angola e de Moçambique, esse eixo deslocou-se para o Brasil, país que surgia como símbolo de emancipação política e cultural para os escritores africanos.

O Brasil representava um modelo a ser seguido, modelo de crescimento, de industrialização e de modernização, em flagrante contraponto com Portugal, que ocupava um lugar de semiperiferia político-econômica e cultural na Europa. Assim, a literatura brasileira teve importante penetração nos países africanos de língua portuguesa, interpondo-se ao modelo literário português e à hegemonia literária europeia.

Dessa forma, no caso específico de Cabo Verde, houve uma aproximação muito grande entre os escritores do arquipélago e o movimento Modernista brasileiro, principalmente, mas não só. Escritores regionalistas e a geração de 45 foram muito lidos nos países africanos de língua portuguesa. A Revista Claridade vai justamente aglutinar o ideário de valorização da caboverdianidade, dos elementos nacionais, andando na direção que foi apontada pelo movimento Modernista para os escritores brasileiros, em que os mais importantes passos foram dados por Mário de Andrade.

Um dos fundadores da revista Claridade foi Manuel Lopes, autor de Os Flagelados do Vento Leste, o que torna mais produtiva a observação dos diálogos que existem entre essa obra e Macunaíma, baluarte do Modernismo brasileiro.

O Modernismo brasileiro teve como projeto estético a valorização da nacionalidade, dos costumes, da língua falada, do nosso folclore, da nossa música, das nossas artes, das nossas origens étnicas, do índio, dos aspectos religiosos, da afrobrasilidade, do nosso povo, da nossa gente, enfim, de todos os elementos culturais brasileiros recalcados e que viviam à sombra dos modelos europeus. A representação cultural desse projeto estético de valorização do nacional, distanciando-o em suas especificidades dos valores europeus, está concretizada 
não só na Semana de Arte Moderna, mas no "Manifesto antropófago" de Oswald de Andrade e no romance Macunaíma.

O romance brasileiro destaca-se por um conjunto de elementos narrativos que convergem para sua singularidade e ousadia formal: irreverência do protagonista; elaboração mais autêntica do folclore e de dados etnográficos; humor; adesão aos elementos recalcados da nossa civilização como o negro, o índio, o mestiço, o filho de imigrantes; a ingenuidade; a malandrice; a metamorfose; anedotas etiológicas; forte oralidade (lendas, cantigas, louvações nordestinas etc.); a presença dos deuses afro-brasileiros (os orixás) e de mitos indígenas. Todo esse conjunto de elementos, que podemos chamar de cênicos, articula-se dentro de uma geografia extremamente dinâmica, um espaço quase mítico e numa atemporalidade em que a busca de um objeto é a espinha dorsal da narrativa em torno da qual os acontecimentos se encadeiam. É um texto rico em metáforas, símbolos e alegorias.

Haroldo de Campos, no livro Morfologia do Macunaíma (2008), faz um estudo associando o romance à estrutura dos contos maravilhosos categorizados por Vladimir Propp. O principal ponto elencado pelo teórico é a estrutura do romance que o faz defini-lo como "romance de busca", uma vez que toda a narrativa gira em torno da busca da muiraquitã. Pensamos, todavia, que um aspecto muito importante que define o conto maravilhoso de Propp, presente em Macunaíma, é o uso de objetos mágicos para dar soluções a impasses ou carências, como é o caso da cabaça mágica e da viola mágica que possibilitam o surgimento de fartura de pescado e de caça para matar a fome de Macunaíma, o herói de nossa gente, e de seus parentes.

Os flagelados do vento leste é um romance que tem forte diálogo com o neo-realismo português, e o modernismo e regionalismo brasileiros. Narrativa poética, também rica em metáforas, símbolos e alegorias, revela um crescimento humano e muita densidade nas personagens, à medida que decorre o entrecho, mostras da grande sensibilidade do escritor. Para Jorge Alfama, o romance

[...] constitui um verdadeiro libelo acusatório em que o autor [...], mantendo-se rigorosamente nos parâmetros da realidade, descreve os horrores que testemunhou na sua ilha 
[...]. [...] de cariz neo-realista, retrata a catástrofe das secas de Santo Antão quando a chuva não abençoa a ilha, a seca a todos atemoriza obrigando a trocar por alimentos tudo o que se pode e, no desespero, a vender os magros haveres e, por último, a própria casa, os animais e a terra que representam o pão do quotidiano (ALFAMA, 1998, p. 241).

A leitura das obras cabo-verdianas revela a presença dos escritores brasileiros no universo literário de Cabo Verde, sobretudo os romances que problematizaram a fome, como $O$ quinze, de Rachel de Queiroz, Vidas Secas, de Graciliano Ramos, ou que trouxeram a oralidade para dentro do discurso poético como é o caso de Macunaíma, de Mário de Andrade, ou de Sagarana, Corpo de Baile e Grande Sertão: Veredas, de Guimarães Rosa. Lembramos, entretanto, que o contato com a matéria literária exógena ou a cultura de outros povos possibilita a absorção e a transformação desse material alheio em contato com o próprio de cada país. Ou seja, há um processo de assimilação e posterior transformação. Ángel Rama explica a transculturação na narrativa como uma dialética entre perda (cultura nativa - parcial desculturação) e incorporação (cultura externa - neoculturação), mistura que gera uma recomposição (cultura nova ou transculturação). Ele exemplifica com a literatura latino-americana produzida por José María Arguedas, Juan Rulfo, Gabriel García Márquez e Guimarães Rosa, já que essas obras são exemplos da transculturação narrativa nos três níveis: linguístico, literário e de cosmovisão (AGUIAR; VASCONCELOS, 2001, p. 216). Pensamos, a propósito, que os diálogos das vanguardas europeias que ressoam em Macunaíma contribuíram para a evidente arquitetura criativa do romance.

Podemos estender a concepção de transculturação para os países africanos de língua portuguesa e particularmente para Cabo Verde, no sentido de identificar como esse processo se manifesta na literatura, e que Antonio Candido, no ensaio "Literatura e subdesenvolvimento" (1988), chamou de "afinamento de instrumentos".

Esse procedimento pode ser exemplificado pelo uso da oralidade e pela apropriação dessa oralidade com impregnações de marcas próprias do autor, ou do contexto linguístico, resultantes geralmente de situações de diglossia, herança da colonização. Podemos citar os seguintes exemplos: a "quechuização" do espanhol por Arguedas; a 
"quimbundização" do português por Luandino; a elevação da linguagem sertaneja à linguagem poética por Guimarães Rosa, e a invasão da oralidade no seu texto poético; o uso da oralidade, de termos africanos e indígenas por Mário de Andrade; o uso de termos de origem banto por José Craveirinha, Luís Bernardo Honwana, Mia Couto e outros escritores moçambicanos; o uso de alguns termos crioulos por Manuel Lopes.

Macunaíma e Os flagelados do vento leste são romances de muita oralidade. Em Macunaíma a oralidade se estende em toda a linguagem, do narrador e das personagens. Já em Os flagelados do vento leste a oralidade, a fala genuinamente popular, está circunscrita às vozes das personagens.

A tradição oral é uma fonte a que recorrem os narradores de todo o mundo, conforme relata Walter Benjamin (1986, p. 221). As tradições orais constituem um manancial de informações do qual fazem parte os contos, as lendas, os mitos, as parlendas, as cantigas, as adivinhas e os provérbios, que se mantêm na oralidade, passando de geração a geração, determinando costumes e comportamentos. Fazem parte do patrimônio imaterial de um povo, e são importantes e fundamentais para a sua formação identitária.

Quando se fala na valorização da brasilidade, ou na valorização da caboverdianidade, ou seja, nos valores genuinamente brasileiros ou cabo-verdianos, fala-se naturalmente nas tradições orais desses povos. E é por essa razão que em Macunaíma há a presença das tradições orais, e em Os flagelados do vento leste também. As tradições orais presentificam-se no texto andradino em cantigas, lamentações, adivinhas, lorotas, anedotas etiológicas, lendas indígenas, mitos, e em máximas e provérbios. O romance Os flagelados do vento leste, diferentemente de Macunaíma, ressente-se da presença de adivinhas, de mitos, de lendas e principalmente de cantigas e lamentações. No entanto, é rico em máximas, aforismos e provérbios que fazem parte das tradições orais do arquipélago.

Naturalmente, nem todos os provérbios foram escritos pelo autor na forma em que são falados, alguns são apropriações e recriações. Pela ausência de fontes primárias, não foi possível diferenciar com certeza os provérbios dos ditos sentenciosos do autor. Como eles cumprem a função de conselhos e de transmissão de conhecimento, por via oral, serão elencados sem essa distinção formal, interessando-nos apenas o sentido deles. 
Os provérbios dizem muito da cultura de um povo, pois ditam normas de bem viver, regras de comportamento, condutas socialmente aceitáveis, conselhos. De acordo com Walter Benjamin (1986, p.221), "os provérbios são ruínas de antigas narrativas, nas quais a moral da história abraça um acontecimento, como a hera abraça o muro", perpetuando-se na oralidade. Sendo assim, é um recurso de construção narrativa dos mais expressivos resgatados da oralidade a que recorrem todos os narradores, apropriando-se dos seus conteúdos culturais. Mário de Andrade e Manuel Lopes recorrerão aos provérbios para enriquecerem suas narrativas de elementos da tradição oral de seus povos, condizentes com o projeto estético de valorização do nacional em suas obras.

Citamos o resgate dos seguintes provérbios da oralidade e seu uso nas obras estudadas:

\section{Em Macunaíma:}

Espinho que pinica de pequeno já traz ponta (ANDRADE, 1978, p. 10).

Por morrer o caranguejo, o mangue não bota luto (Ibidem, p. 49).

Quem quer cavalo sem tacha anda de a-pé (Ibidem, p. 50).

Primeira pancada é que mata cobra (Ibidem, p. 53).

Quando míngua a luna não comeces coisa alguma (Ibidem, p. 73).

Quem não trabuca, não manduca (Ibidem, p. 143).

Antes só que mal acompanhado (Ibidem, p. 47).

Amor primeiro não tem companheiro (Ibidem, p. 34).

Gato miador, pouco caçador (Ibidem, p. 122).

Como já foi dito, Macunaíma é um romance de estrutura oral por excelência. E quando o autor não reescreve os provérbios do modo em que são ditos popularmente, ele 
também os inverte e parodia, obtendo um efeito de humor. Exemplos: "Diabo leve quem trabalha", parodiando "Deus ajuda quem trabalha". Ou então, ele adapta um provérbio formulando um dito sentencioso: "Antes fanhoso do que sem nariz", a significar "Dos males o menor". Em Macunaíma, a quantidade de provérbios é muito inferior aos do romance cabo-verdiano. No entanto, no romance brasileiro os recursos estilísticos utilizados são inúmeros, abarcando uma multiplicidade e diversidade de aspectos da tradição oral que resgatam, como já foi mencionado anteriormente.

Em Os flagelados do vento leste, detectamos as seguintes ocorrências de provérbios e suas adaptações:

Homem que não traça caminho é falso (LOPES, 1979, p. 14).

Andar no caminho ruim é melhor que andar fora de caminho (Ibidem, p. 16).

Quem com os ouvidos não ouve, com os olhos não vê (Ibidem, p. 29).

Homem desconfiado não presta (Ibidem, p. 35).

Quem mais sede tem, com mais água sonha (Ibidem, p. 36).

Infância de menino de campo é isto: trocar as mamas da mãe pelo cabo da enxada do pai (Ibidem, p. 50).

O que fica feito não fica por fazer (Ibidem, p. 51).

Deus dá remédio pra tudo (Ibidem, p. 109).

Homem na falta é diferente de homem na fartura (Ibidem, 130).

Sonhar não faz mal a ninguém, mas não transforma nada em milho para comer, nem em cama para dormir, nem em teto para cobrir a casa (Ibidem, p. 140).

Todo mundo é igual cando as coisas andam mal ou andam bem na igualdade (Ibidem, p. 145).

Morte de povo não é sentida (Ibidem, p. 145). 
Deus é grande (Ibidem, p. 152).

Um homem é um homem, um gato é um bicho (Ibidem, p. 225).

Morte entra no corpo que não trabalha (Ibidem, p.225).

Cada um conhece a mandioca da sua horta (Ibidem, p. 263).

Mas cando Deus dá a chuva o que é perdido é ganhado (Ibidem, p. 31).

É Deus que dá, é Deus que leva (Ibidem, p. 117).

Homem que sabe escrever no papel não esquece na cabeça (Ibidem, p.58).

Nunca ouviu dizer que olho de dono é que engorda a vaca? (Ibidem, p. 211).

$\mathrm{O}$ resgate das tradições orais para dentro do universo literário, como fizeram os autores estudados, constitui-se em grande contribuição que a literatura presta à sociedade, pois significa a preservação das tradições, a ativação da memória, o fortalecimento da identidade, a defesa do patrimônio imaterial de um povo e isso interessa à história desse povo.

As tradições orais são formadoras da identidade cultural de um povo, e revivê-las, pela oralidade ou por intermédio da literatura, para que elas não desapareçam caindo no esquecimento, é uma forma de resistência cultural frente às culturas que interagem nos mundos culturais, sobretudo nos processos de globalização, trânsito intenso de culturas, de bens e de pessoas, que impactam as identidades modificandoas ou criando novas identidades, como bem postulado por Stuart Hall (2006).

Para o antropólogo jamaicano, as identidades nacionais são construídas por "intermédio da narrativa da nação tal como ela é contada nas histórias e nas literaturas nacionais, na mídia e na cultura popular" (HALL, 2006, p.52). É nesse sentido que as tradições orais, quando dinamizadas, fortalecem a identidade nacional e a identidade cultural de um povo.

Eric Hobsbawm, no livro A invenção das tradições (2002), lembra que o povo que preserva suas tradições orais não 
precisa inventá-las, processo comum quando há perda de identidade em situações de colonização. Para Adorno (2003, p.164), o artista, portador da obra de arte, não é apenas aquele indivíduo que a produz, mas sim torna-se o representante, por meio de seu trabalho e de sua passiva atividade, do sujeito social coletivo. Nesse sentido, a representação literária das tradições orais de um povo é a representação de todo o povo por um sujeito social coletivo, o escritor. E Mário de Andrade e Manuel Lopes deram essa contribuição ao seu povo.

\section{REFERÊNCIAS}

ABDALA JUNIOR, Benjamin. De voos e ilhas - literatura e comunitarismos. São Paulo: Ateliê, 2003.

ADORNO, Theodor. Notas de literatura I. São Paulo: Duas Cidades/Ed. 34, 2003.

AGUIAR, Flávio e VASCONCELOS, Sandra Guardini (Orgs). Angel Rama: literatura e cultura na América Latina. São Paulo: Edusp, 2001.

ALFAMA, Jorge. Os flagelados do vento leste. In VEIGA, Manuel. Cabo Verde - insularidade e literatura. Paris: Karthala, 1998.

ANDRADE, Mário de. Macunaíma - o herói sem nenhum caráter. São Paulo: Martins Fontes, 1978.

ANDRADE, Oswald de. Manifesto antropófago. In: TELES, Gilberto Mendonça. Vanguarda européia e modernismo brasileiro: apresentação e crítica dos principais manifestos vanguardistas. 3 ed. Petrópolis: Vozes; Brasília: INL, 1976.

ARGUEDAS, José María. Los ríos profundos. Lima: Horizonte, 2001.

BENJAMIN, Walter. Magia e técnica, arte e politica: ensaios sobre literatura e história da cultura. São Paulo: Brasiliense, 1987.

CAMPOS, Haroldo de. Morfologia do Macunaíma. 2. ed. São Paulo: Perspectiva, 2008.

CANDIDO, Antonio. Formação da literatura brasileira: momentos decisivos. v. I. São Paulo: Itatiaia, 1975. 
CANDIDO, Antonio. Literatura e subdesenvolvimento. In: A educação pela noite e outros ensaios. São Paulo: Cia. Editora Nacional, 1976.

CARVALHAL, Tânia Franco. O próprio e o alheio: ensaios de literatura comparada. São Leopoldo: Unisinos, 2003.

COUTO, Mia. Cronicando. 4. ed. Lisboa: Caminho, 1991.

CRAVEIRINHA, José. Hamina e outros contos. Lisboa: Caminho, 1998.

D'ALMEIDA, José Evaristo. O escravo. (1989). Prefácio Manuel Veiga. 2. Ed. Lisboa: ALAC. Disponível em: <https://app.box. com/s/5o4klvapee1wnlv799ep>. Consultado em: 25.01.2015.

FERREIRA, Manuel (Org.). Claridade - Revista de Arte e Letras. Edição Facsimilar. Lisboa: ALAC, 1986.

GOMES, Simone Caputo. (2008). “Olhares transversais da escrita literária sobre a cultura identitária do arquipélago: do dilema do "primeiro" romance cabo-verdiano à produção contemporânea". Anais do XI Congresso Internacional da ABRALIC. Disponível em: < http://www.abralic.org.br/ anais/cong2008/AnaisOnline/simposios/pdf/001/SIMONE_ GOMES.pdf >. Consultado em: 25.01.2015.

HALL, Stuart. A identidade cultural na pós-modernidade. São Paulo: DP\&A, 2006.

HOBSBAWM, Eric e RANGER, Terence. A invenção das tradições. Trad. Celina Cardim Cavalcante. Col. Pensamento Crítico, v. 55, Rio de Janeiro: Paz e Terra, 2002.

HONWANA, Luís Bernardo. Nós matamos o cão tinhoso. São Paulo: Ática, 1980.

LOPES, Baltasar. Chiquinho. São Paulo: Ática, 1986.

LOPES, Manuel. Os flagelados do vento leste. São Paulo: Ática, 1979.

MÁRQUEZ, Gabriel García. Cem anos de solidão. Rio de Janeiro: José Olympio, 1976.

PERRONE-MOISÉS, Leyla. Flores na escrivaninha. São Paulo: Cia. das Letras, 1990. 
PROPP, Vladimir I. Morfologia do conto maravilhoso. Trad. Jasna Paravich Sarthan. Rio de Janeiro: Forense, 1984.

QUEIRÓZ, Rachel de. O quinze. Rio de Janeiro: José Olympio, 2004.

RAMOS, Graciliano. Vidas secas. Rio de Janeiro: Record, 2010. ROSA, João Guimarães. Sagarana. Rio de Janeiro: Nova Fronteira, 2006.

. Grande Sertão: Veredas. Rio de Janeiro: Nova Fronteira, 2006. . Corpo de Baile. Rio de Janeiro: Nova Fronteira, 2010.

RULFO, Juan. Pedro Páramo. México: Fondo de Cultura Económica, 1998.

SILVA, Avani Souza. Guimarães Rosa e Mia Couto: ecos do imaginário infantil. Dissertação de Mestrado, Universidade de São Paulo, 2007. Disponível em: <http://www.teses.usp. br/teses/disponiveis/8/8156/tde-02102007-140711/pt-br.php>. Consultado em: 30.01.2015. 


\section{Abstract \\ Macunaima, by Mário de Andrade, and Os flagelados do vento leste, by Manuel Lopes: magical readings of oral tradition}

The main goal of this paper is to interpret, via Comparatism of solidarity (ABDALA JUNIOR, 2003), two works belonging to the literary macro system of Portuguese literature: Macunaima (1928), by Brazilian writer Mário de Andrade, and Os flagelados do vento leste (1968), by CapeVerdean Manuel Lopes. We will examine the oral marks in both works, highlighting their points of contact and rupture regarding the socio-cultural contexts in which they were produced. To justify the comparison, it is vital to point out that one of the postulates claimed by the cultural movement of "capeverdianism" - to which Manuel Lopes belonged - was one also claimed by Brazilian Modernism, that of valuing the national aesthetics, particularly its oral tradition.

Keywords: literary macro system, oral tradition, Cape-Verdean literature, comparative literature, Comparatism of solidarity. 